\title{
Seismotectonics of Bhutan: Evidence for segmentation of the Eastern Himalayas and link to foreland deformation
}

\author{
Tobias Diehl $^{\mathrm{a}, *}$, Julia Singer ${ }^{\mathrm{b}}$, György Hetényi ${ }^{\mathrm{a}, \mathrm{b}, \mathrm{c}}$, Djordje Grujic ${ }^{\mathrm{d}}$, John Clinton ${ }^{\mathrm{a}}$, \\ Domenico Giardini $^{\text {b }}$, Edi Kissling ${ }^{\text {b }}$, GANSSER Working Group ${ }^{1}$ \\ a Swiss Seismological Service, ETH-Zürich, 8092 Zurich, Switzerland \\ b Institute of Geophysics, ETH-Zürich, 8092 Zurich, Switzerland \\ ${ }^{\mathrm{c}}$ Institute of Earth Sciences, University of Lausanne, 1015, Switzerland ${ }^{2}$ \\ d Department of Earth Sciences, Dalhousie University, Halifax NS B3H 4R2, Canada
}

\section{A R T I C L E I N F O}

\section{Article history:}

Received 28 January 2017

Received in revised form 19 April 2017

Accepted 21 April 2017

Available online $\mathrm{xxxx}$

Editor: P. Shearer

\section{Keywords:}

Bhutan

seismicity

local earthquake tomography

Main Himalayan Thrust

Dhubri-Chungthang fault zone

Shillong plateau

\begin{abstract}
A B S T R A C T
The instrumental record of Bhutan is characterized by a lower seismicity compared to other parts of the Himalayan arc. To understand this low activity and its impact on the seismic hazard, a seismic network was installed in Bhutan for 22 months between 2013 and 2014. Recorded seismicity, earthquake moment tensors and local earthquake tomography reveal along-strike variations in structure and crustal deformation regime. A thickened crust imaged in western Bhutan suggests lateral differences in stresses on the Main Himalayan Thrust (MHT), potentially affecting the interseismic coupling and deformation regime. Sikkim, western Bhutan and its foreland are characterized by strike-slip faulting in the Indian basement. Strain is particularly localized along a NW-SE striking mid-crustal fault zone reaching from Chungthang in northeast Sikkim to Dhubri at the northwestern edge of the Shillong Plateau in the foreland. The dextral Dhubri-Chungthang fault zone (DCF) causes segmentation of the Indian basement and the MHT between eastern Nepal and western Bhutan and connects the deformation front of the Himalaya with the Shillong Plateau by forming the western boundary of the Shillong block. The Kopili fault, the proposed eastern boundary of this block, appears to be a diffuse zone of mid-crustal seismicity in the foreland. In eastern Bhutan we image a seismogenic, flat portion of the MHT, which might be either related to a partially creeping segment or to increased background seismicity originating from the 2009 $M_{\mathrm{W}} 6.1$ earthquake. In western-central Bhutan clusters of micro-earthquakes at the front of the HighHimalayas indicate the presence of a mid-crustal ramp and stress buildup on a fully coupled MHT. The area bounded by the DCF in the west and the seismogenic MHT in the east has the potential for M7-8 earthquakes in Bhutan. Similarly, the DCF has the potential to host $M 7$ earthquakes as documented by the 2011 Sikkim and the 1930 Dhubri earthquakes, which were potentially associated with this structure.
\end{abstract}

(C) 2017 Elsevier B.V. All rights reserved.

\section{Introduction}

The ongoing convergence between India and Asia has produced several megathrust earthquakes $(M \geq 7.5)$ in the Himalayas and at the Shillong Plateau in the eastern foreland (Fig. 1A). The analysis of historical megathrust earthquakes and geodetic rates along the Himalayan arc suggest that similarly devastating earthquakes are overdue in several parts of the Himalaya (Bilham and England, 2001; Avouac et al., 2015; Stevens and Avouac, 2016). The Bhutan

\footnotetext{
* Corresponding author. Fax: +41446331065.

E-mail address: tobias.diehl@sed.ethz.ch (T. Diehl).

1 Members of the GANSSER Working Group are G. Hetényi, J. Chophel, J. Clinton,

T. Diehl, D. Drukpa, D. Giardini, E. Kissling, and J. Singer.

2 Pressent address.
}

Himalaya has been previously identified as an apparent gap in recent instrumental seismicity (Gahalaut et al., 2011). The relatively low activity in instrumentally recorded seismicity in Bhutan is apparent in global earthquake bulletins such as the USGS/NEIC catalog shown in Fig. 1. Bilham and England (2001) suggested that this seismic gap could be the result of strain partitioning, in which up to one third of the total shortening of $18 \mathrm{~mm} / \mathrm{yr}$ in the Eastern $\mathrm{Hi}$ malayas can be accommodated by the basement-cored uplift of the Shillong Plateau in the foreland (Fig. 1B). The proposed reduction in shortening rate across the Bhutan Himalayas, however, is inconsistent with recent geodetic studies (e.g., Banerjee et al., 2008). The contraction rate of $14-17 \mathrm{~mm} / \mathrm{yr}$ across Bhutan seems only slightly smaller than in Nepal (Vernant et al., 2014; Marechal et al., 2016) and the net convergence between India and Tibet (including shortening accommodated by the Shillong Plateau) is therefore 


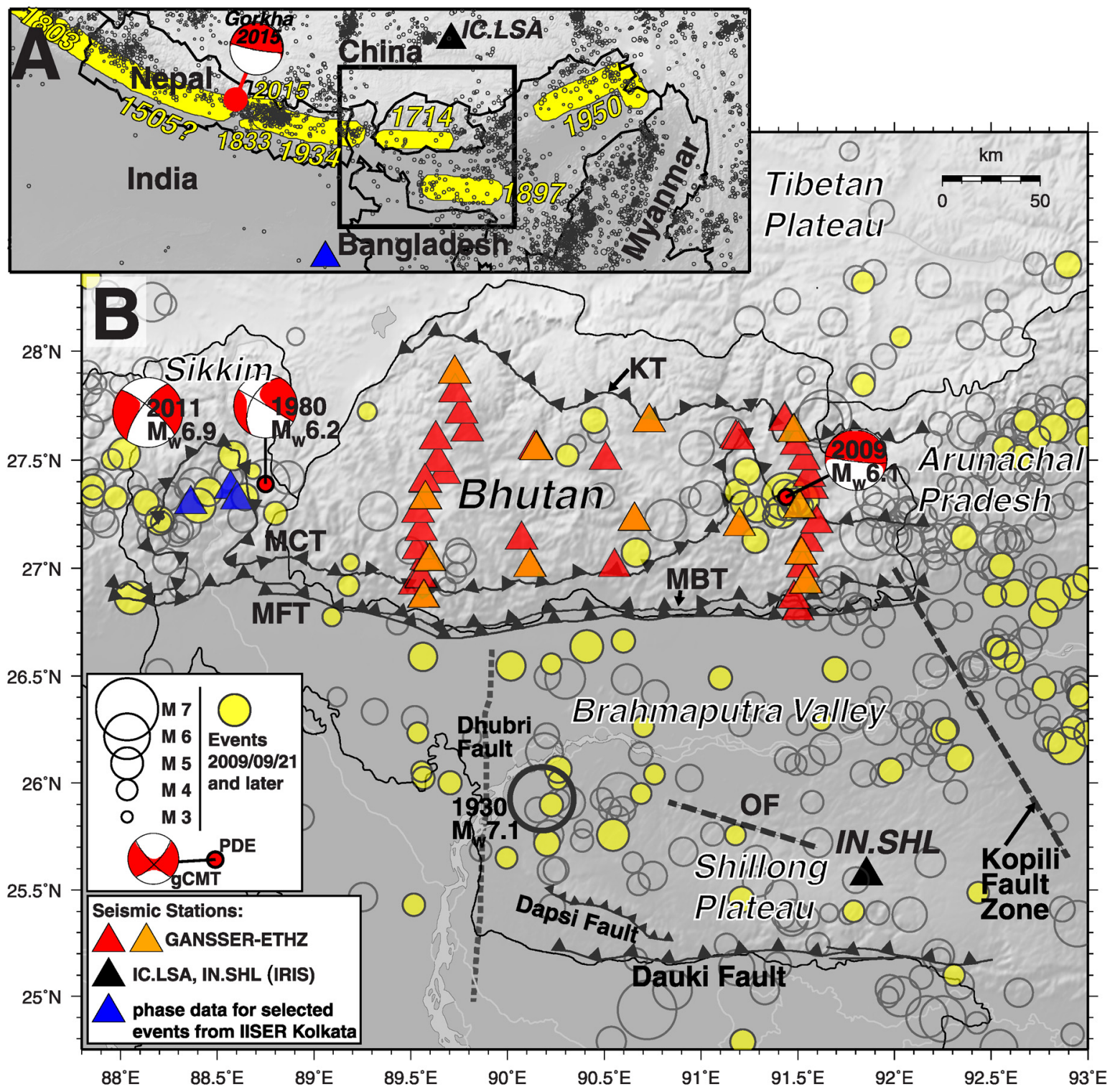

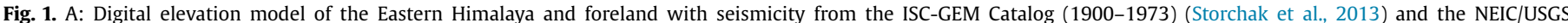

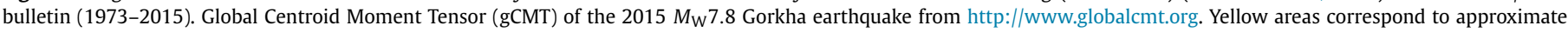

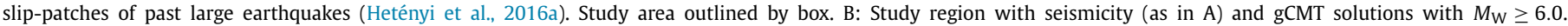

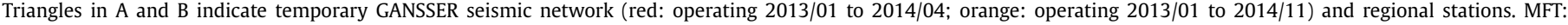

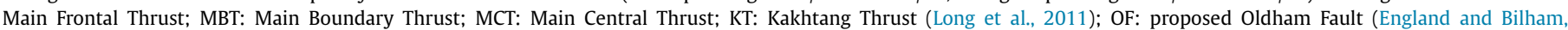

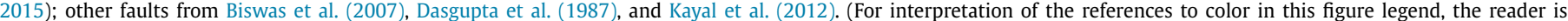
referred to the web version of this article.)

larger across Bhutan than across Nepal, consistent with the general increase in convergence towards the eastern syntaxis (Burgess et al., 2012).

Recent paleoseismic studies along the Main Frontal Thrust (MFT) in Bhutan suggest the occurrence of one or more large earthquakes in the last millennium (Berthet et al., 2014; Le RouxMallouf et al., 2016). Re-interpretation of historical damage reports provides additional evidences for an $M 8$ earthquake in Bhutan in $1714 \mathrm{AD}$ (Fig. 1A), suggesting that there are no gaps in large earthquakes along the entire Himalayan arc (Hetényi et al., 2016a). Assuming that no great earthquake occurred since 1714, the presentday convergence rates suggest a slip potential of about $5 \mathrm{~m}$ in Bhutan (Vernant et al., 2014). The Main Himalayan Thrust (MHT) represents the basal décollement between the orogenic wedge and the underthrusting Indian basement and is the source of megathrust earthquakes in the Himalayas (e.g., Seeber et al., 1981). Its geometry is crucial for estimates of stress-accumulation and assessing potential rupture sizes. The MHT is not a continuous flat thrust but is characterized by a frontal ramp, the MFT, a flat segment, and a mid-crustal ramp. The former is evident from surface geology. The latter two segments have been previously imaged by the INDEPTH data (Hauck et al., 1998) and its geometry has been modeled by various datasets. Based on the joint inversion of denudation rates, GPS data, and Holocene uplift, Le Roux-Mallouf et al. (2015) find evidence for a wide MHT in western Bhutan. Their model predicts a steep mid-crustal ramp along the MHT at about $130 \mathrm{~km}$ north of the MFT, indicating a wider décollement compared to central Nepal and Sikkim. Models based on thermochronologic data, however, estimate a steepening of the MHT in western Bhutan further to the south, around $90 \mathrm{~km}$ north of the MFT (Coutand et al., 2014). This geometry is consistent with receiver function images (Singer et al., 2017a) and closer to struc- 
tures elsewhere in the Himalaya. Based on the analysis of continuous and campaign GPS data, Marechal et al. (2016) proposed a fully coupled, 135-155 km wide MHT in western and central Bhutan. For eastern Bhutan, their model suggests a 100-120 km wide fully coupled MHT, with evidence for partially creeping segments at the frontal ramp close to the MFT and down-dip towards the north at the mid-crustal ramp.

Due to the absence of local seismic monitoring networks, information on the crustal structure, currently active faults, and fault geometries in Bhutan is sparse. Previous seismotectonic studies in the Bhutan Himalaya were therefore limited in resolution. From the analysis of regional earthquake data, Drukpa et al. (2006) found evidence for dominant strike-slip deformation throughout the crust in Bhutan. A 14-mo deployment of five seismic stations in Bhutan between January 2002 and March 2003 revealed a NW-SE striking cluster of micro-seismicity in the southwestern part of the country (Velasco et al., 2007). De and Kayal (2003) observed a similar cluster of earthquakes with networks deployed in the SikkimDarjeeling Himalaya between 1993 and 1999. They suggested that earthquakes in southwestern Bhutan are part of a 200-km-long NW-SE trending transverse structure, which cuts across the major Himalayan thrust faults and extends to the Goalpara wedge in the foreland. On a regional scale, De and Kayal (2003) propose the Goalpara lineament as possible link between seismicity in the Sikkim Himalaya and the Shillong Plateau. The NW-SE trending seismogenic structure imaged by local networks, however, is not resolved by global earthquake bulletins such as the NEIC/USGS catalog (Fig. 1). Kayal et al. (2012) propose a corresponding continuation of the dextral Kopili fault (Fig. 1B) from the foreland towards the Main Central Thrust (MCT) in eastern Bhutan. Dasgupta et al. (1987) proposed similar transverse lineaments (e.g. the Yamuna lineament as the northward continuation of the Dhubri fault, see Fig. 1) extending from the foreland to the Himalaya and of which several are optimally oriented to be activated in the regional stress field.

The continuation of foreland faults beneath the Eastern $\mathrm{Hi}$ malaya and the subdivision of the incoming Indian Plate east of $87^{\circ} \mathrm{E}$ into several blocks is also proposed by the GPS model of Vernant et al. (2014). They defined the Kopili fault (Fig. 1B) as the eastern boundary of a Shillong block (SLB), which underthrusts the Himalaya of Bhutan. Their model predicts clockwise rotation of the SLB, resulting in 2-3 mm/yr dextral slip along the Kopili fault, similar to other studies (e.g., Barman et al., 2014). Dextral slip along the proposed NW-SE oriented western boundary of the SLB block is $0.8 \mathrm{~mm} / \mathrm{yr}$.

The passive seismic experiment Geodynamics ANd Seismic Structure of the Eastern Himalaya Region (GANSSER) was designed to image lithospheric structures and active faults at high resolution, necessary to further constrain the current understanding of neotectonic processes and their impact on the seismic hazard in Bhutan and its foreland. In this study, we present the first high-resolution earthquake catalog and 3-D crustal P-wave velocity model of Bhutan derived from the GANSSER experiment. With additional information from moment tensor inversion, combined with recent findings from receiver functions, geology, and geodesy, we provide new insights into the present-day seismotectonics of the Bhutan Himalaya and its foreland.

\section{GANSSER earthquake catalog}

\subsection{Data and methods}

To image seismically active faults and their kinematics in Bhutan and surrounding regions, we perform state-of-the-art earthquake location and moment tensor inversion. We use continuous waveform data recorded by the GANSSER network (Swiss
Seismological Service at ETH Zurich, 2013) between January 2013 and November 2014 (Fig. 1B). The network consisted of 38 threecomponent broadband seismometers (24 Streckeisen STS2 and 14 Nanometrics Trillium Compact) alongside Nanometrics Taurus digitizers recording at a sampling frequency of $100 \mathrm{~Hz}$. To improve detection and hypocenter locations outside the GANSSER network, the dataset was complemented with continuous data from station IC.LSA in Tibet and IN.SHL in northern India (Fig. 1), obtained from the Incorporated Research Institutions for Seismology (IRIS). The Indian Institute of Science Education and Research Kolkata (IISER Kolkata) provided phase data for 22 selected events of stations in Sikkim and West Bengal (Fig. 1; Paul et al., 2015; Thirunavukarasu et al., 2017) to close the azimuthal gap angle for those earthquakes in Sikkim, western Bhutan, and the foreland.

Event-triggers are derived from short-term average (STA) to long-term average (LTA) ratios of all continuous data streams and the entire automatic event detection process is handled within the SeisComP3 monitoring software (Hanka et al., 2010; http://www.seiscomp3.org) optimized for local to regional seismicity. A local magnitude $\left(M_{\mathrm{L}}\right)$ is determined for all automatic and subsequent manual locations. The $M_{\mathrm{L}}$ magnitude is derived from amplitudes measured on the vertical component of the seismogram in combination with the attenuation function of Richter (1935). All automatic earthquake detections were manually reviewed and consistently re-picked using the quality-weighting scheme for $\mathrm{P}$ and $\mathrm{S}$ phases shown in Table S1. Final hypocenters were derived with the probabilistic earthquake location algorithm Nonlinloc (Lomax et al., 2000) in combination with 1-D P- and $\mathrm{S}$-wave velocity models computed for Bhutan, including station corrections (Singer et al., 2017a). To further improve the precision of hypocenters in eastern Bhutan, we applied the doubledifference algorithm hypoDD (Waldhauser and Ellsworth, 2000), in combination with waveform cross-correlation, to a subset of events.

The final catalog consists of 870 events in Bhutan and surrounding regions and magnitudes range from $M_{\mathrm{L}} 0.3$ to 5.4 (Fig. 2). The magnitude of completeness $\left(M_{C}\right)$ is estimated by the probabilistic approach of Schorlemmer and Woessner (2008) and varies between 2.5 to 3.0 within most parts of Bhutan (Fig. S1), with changing detection thresholds during the Indian Summer Monsoon seasons and network configuration (Fig. 2). In agreement with the probabilistic approach, the frequency-magnitude distribution of seismicity in Bhutan indicates an $M_{C}$ of 2.5 , and the derived bvalue of $0.8 \pm 0.1$ (Fig. S2A) might be indicative for an increased differential stress, expected for a collisional belt (Schorlemmer et al., 2005). The entire GANSSER earthquake catalog is provided in digital form in the electronic supplement. For 22 earthquakes, we derive moment tensor solutions with $M_{\mathrm{W}}$ ranging from 3.3 to 4.7 (blue beach-balls in Fig. 3) by applying full-waveform, timedomain linear inversion implemented in the SeisComP3-module SCMTV. The comparison of $M_{\mathrm{L}}$ with $M_{\mathrm{W}}$ indicates an average overestimation of $M_{\mathrm{L}}$ by $0.8 \pm 0.2$ units (Fig. S2b). Three additional focal mechanisms were derived from the analysis of first-motion P-wave polarities (black beach-balls in Fig. 3). The catalog of derived moment tensors and focal mechanisms is provided in the electronic supplement.

\subsection{Results}

The derived earthquake catalog reveals regions of enhanced seismicity in SW Bhutan (C1 in Fig. 3), NW Bhutan (C2 in Fig. 3), and eastern Bhutan (C3 in Fig. 3). The apparent low seismicity in central Bhutan might be an artifact due to the laterally variable $M_{C}$ (Fig. S1A). Both clusters in western Bhutan (C1, C2) resemble patterns resolved by Velasco et al. (2007), indicating that these clus- 


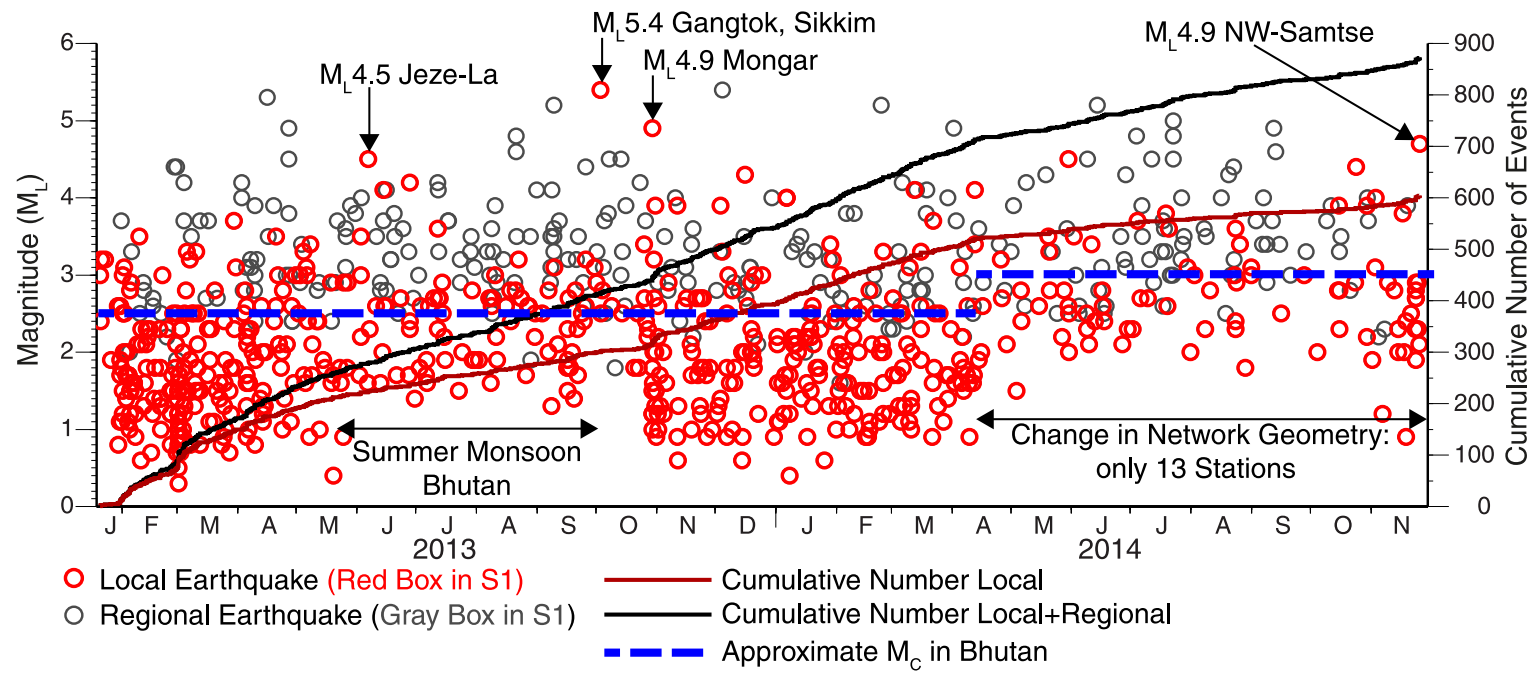

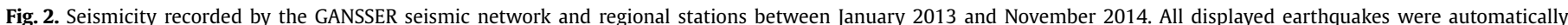

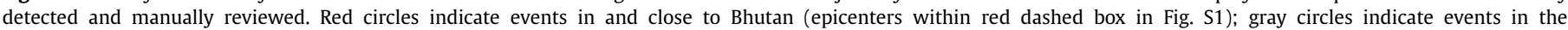

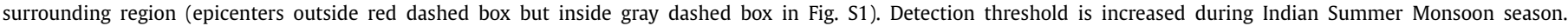

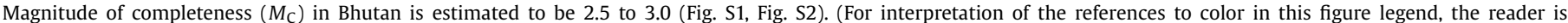
referred to the web version of this article.)

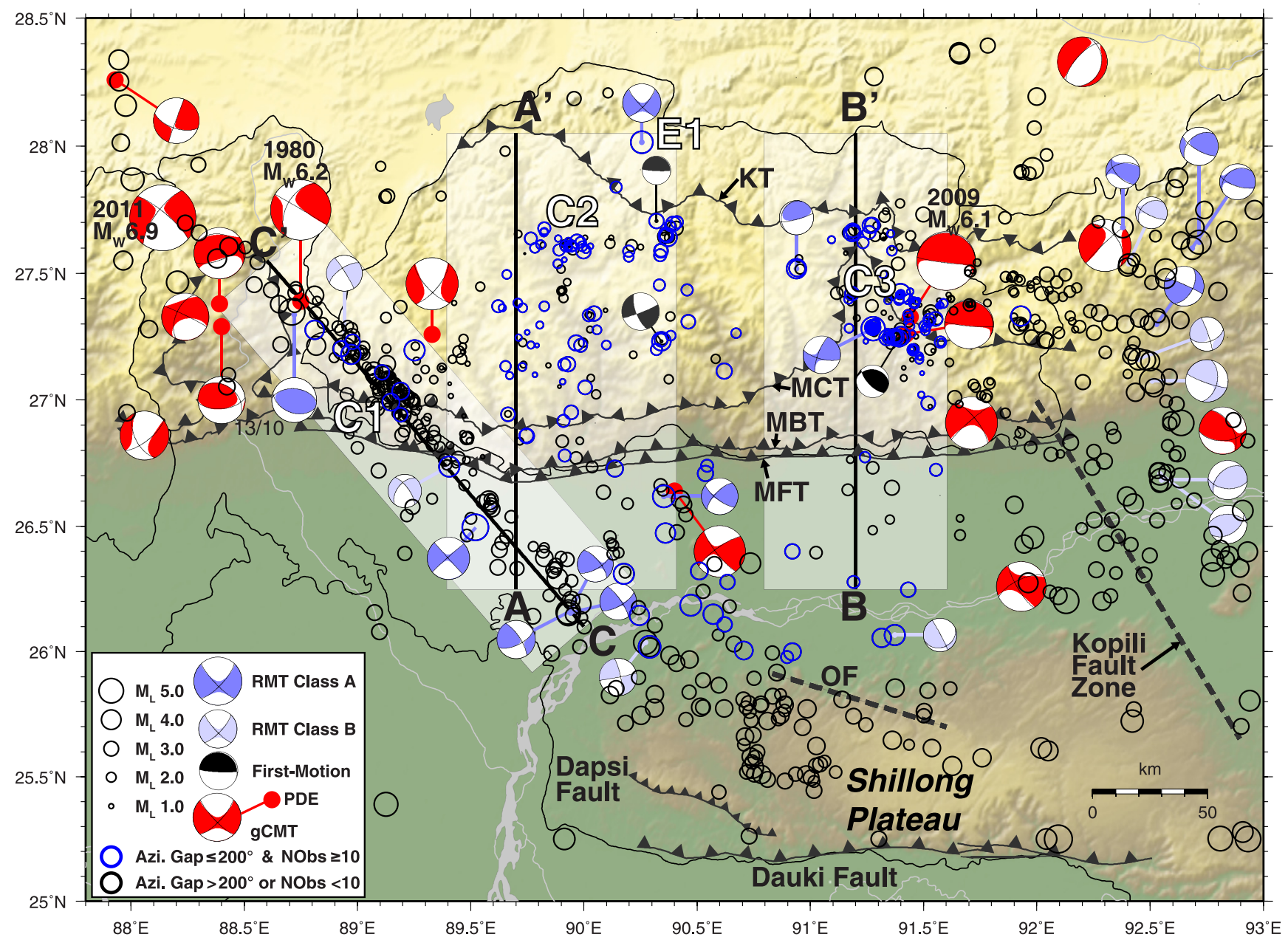

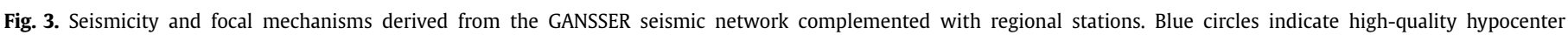

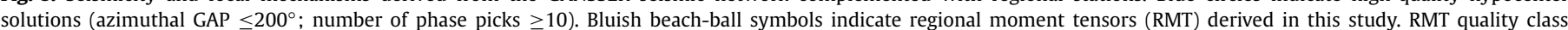

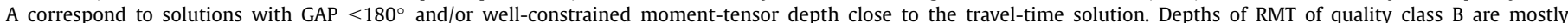

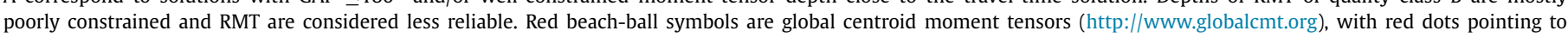

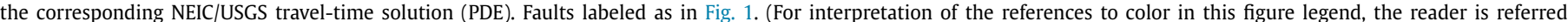
to the web version of this article.) 


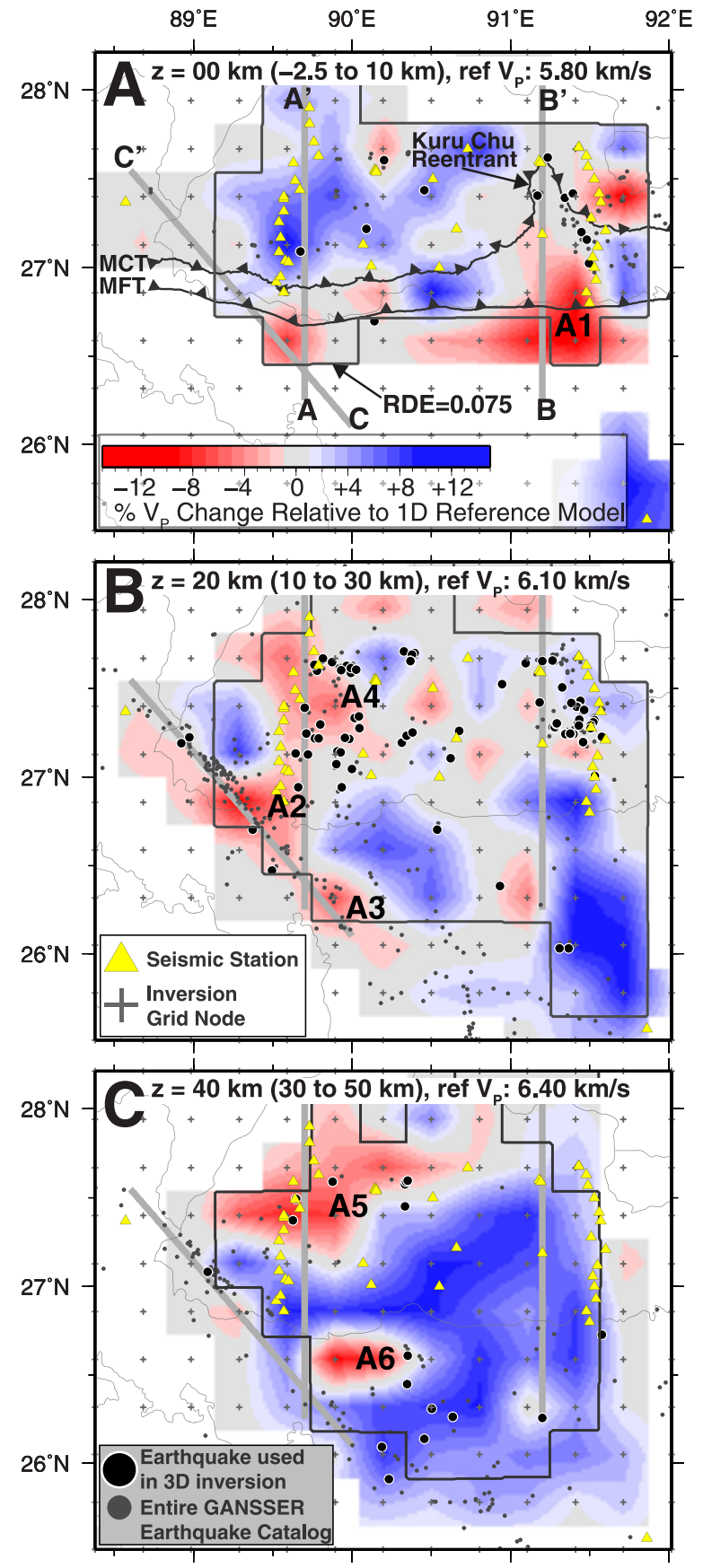

Fig. 4. Three-dimensional $V_{P}$ local earthquake tomography model represented as horizontal cross-sections at three depth levels. The $V_{P}$ velocity structure is shown as percentage change relative to the 1 -D initial reference model. Depths of crosssections, depth intervals, and reference velocities as indicated. Bold black contours outline regions with resolution diagonal elements $(\mathrm{RDE}) \geq 0.075$ and, based on resolution tests, include mostly well to fairly-well resolved parts of the tomographic model (see Fig. S3). Areas outside are considered fairly to poorly resolved (see Fig. S3). Bold black dots indicate earthquakes in corresponding depth interval used for tomographic inversion. Gray dots represent entire GANSSER catalog for corresponding depth interval. A1-A6 mark anomalies discussed in the text. Gray lines indicate position of vertical profiles shown in Fig. 5. Faults labeled as in Fig. 1.

ters are persistently active. In western Bhutan, earthquakes occur almost exclusively below the MHT (Fig. 4A, 4B, 5A) and moment tensors in Fig. 3 indicate therefore strike-slip faulting occurs in the Indian basement up to $76 \mathrm{~km}$ depth (E1 in Fig. 3, 5A), as proposed by others (e.g., Drukpa et al., 2006; Paul et al., 2015).

Cluster C1 is part of a $20 \mathrm{~km}$ wide, NW-SE striking band of seismicity extending from Chungthang in NE Sikkim to Dhubri at the northwestern edge of the Shillong Plateau in the foreland. Moment tensor solutions within cluster $\mathrm{C} 1$ indicate a dextral fault zone (Fig. 3) and deep earthquakes in northern Sikkim, like the $M_{\mathrm{W}} 6.9$ event of 2011 (focal depth of about $50 \mathrm{~km}$; e.g., Paul et al., 2015), likely belong to the same structure. The position and strike of cluster C1 suggests that it coincides with the seismicity clusters identified by De and Kayal (2003) and Velasco et al. (2007), who associate this structure to the geomorphological Goalpara lineament. Since strike and position of cluster C1 significantly deviates from the Goalpara lineament (e.g., De and Kayal, 2003), we name this structure the Dhubri-Chungthang Fault Zone (DCF). The DCF is located outside the GANSSER network, which partly leads to increased location uncertainties, particularly in focal depths (Fig. 5C). For a small subset of events, additional phase data from stations in Sikkim provided reliable focal depths estimates for the DCF (Fig. 3; Fig. 5C). Most of the earthquakes in the DCF occur in the Indian basement between 20 and $40 \mathrm{~km}$ depth (Fig. 5C) with a tendency to deeper focal depths towards northern Sikkim, as also suggested by others (e.g., De and Kayal, 2003).

Micro-earthquakes of cluster C2 in western Bhutan (Fig. 3; Fig. 5A) are located in front of the High Himalaya, mainly in the hanging wall block of the mid-crustal ramp of the MHT, as defined by Hauck et al. (1998), Coutand et al. (2014), and Singer et al. (2017a). Double-difference relocations of cluster C3 in eastern Bhutan image a sub-horizontal seismogenic structure at about $12 \mathrm{~km}$ depth (Fig. 5B), consistent with the hypocenter of the $2009 M_{\mathrm{w}} 6.1$ earthquake and therefore likely associated with the MHT. A deepening of seismicity occurs $95 \mathrm{~km}$ north of the MFT (Fig. 5B), suggesting the location of the mid-crustal ramp in eastern Bhutan.

\section{3-D crustal P-wave velocity structure}

\subsection{Data and methods}

We used high-quality travel-time data from the derived local earthquake catalog to image the 3-D crustal P-wave velocity structure of Bhutan on a $30 \times 30 \times 20 \mathrm{~km}$ grid. For the 3 -D tomographic inversion, 133 events with an azimuthal gap $\leq 180^{\circ}$ and $\geq 8 \mathrm{P}$ phase observations were selected. The travel time data consists of 1809 phases with an average picking error of $0.06 \mathrm{~s}$ (Table S1). With the chosen parameterization, an average over determination factor of 1.3 is achieved. We use the SIMULPS14 software (e.g., Eberhart-Phillips, 1990), which solves the non-linear, coupled hypocenter-velocity problem by a linearized, iterative, damped, least-square approach. Damping of 100 was chosen by the typical assessment of trade-off curves calculated for a range of values. The initial reference model is the 1-D model of Singer et al. (2017a). The solution converges after 3 iterations and the final weighted root mean square of all travel-time residuals is $0.09 \mathrm{~s}$. The resolution of the tomographic model is assessed through a series of synthetic tests described in Fig. S3. Recovery of synthetic structures is mostly well to fairly-well in regions with resolution diagonal elements (RDE) $\geq 0.075$ (Fig. S3) and defines the cut-off value for resolved parts of the model in Figs. 4 and 5.

\subsection{Results}

Within the uppermost layer of the 3-D P-wave model, velocities in southeast Bhutan are significantly lower than in central and western Bhutan (A1 in Fig. 4A). This low-velocity anomaly can be partly associated with sediments in the foreland southeast of Bhutan. We interpret the reduced velocity north of A1 with the exposure of rocks of the Lesser Himalayan Sequence (LHS) beneath the Greater Himalaya Sequence (GHS) within the Kuru Chu reentrant of the MCT (Fig. 4A). At mid-crustal levels, a NW-SE 


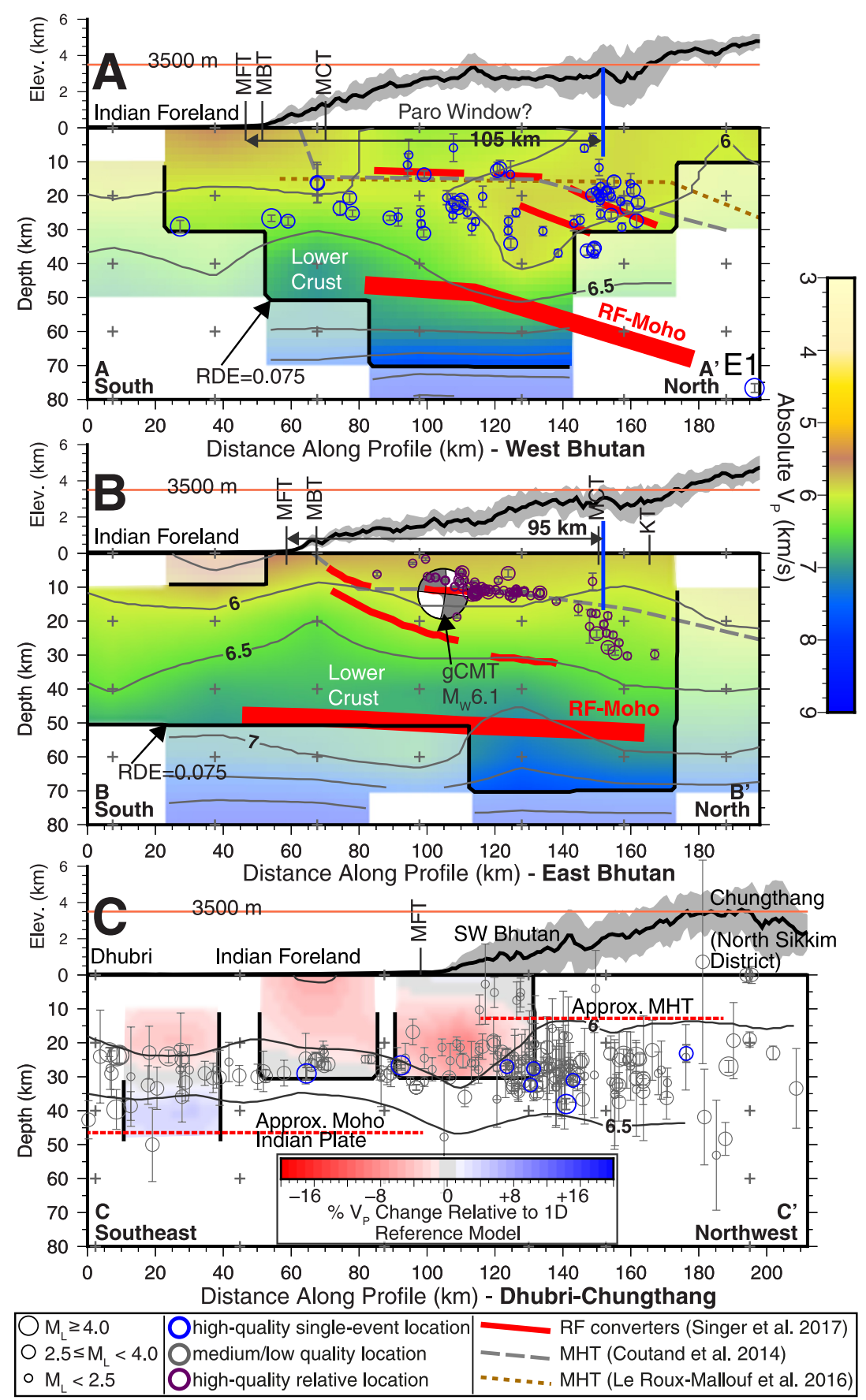

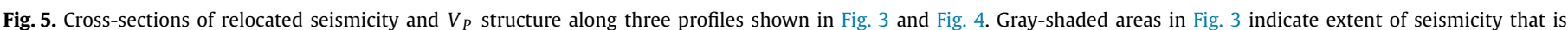

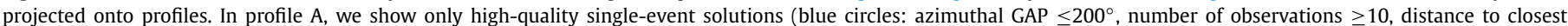

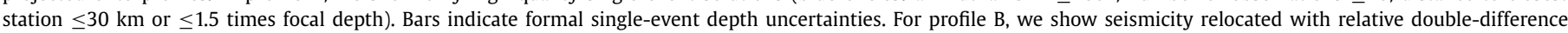

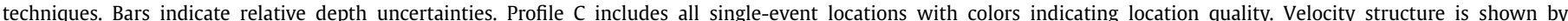

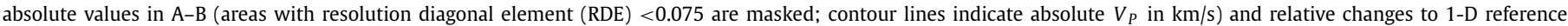

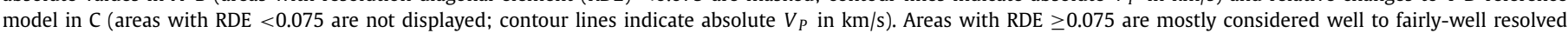

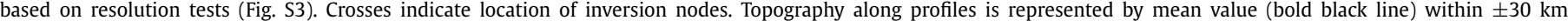

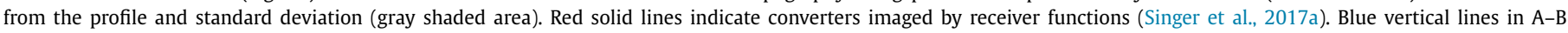

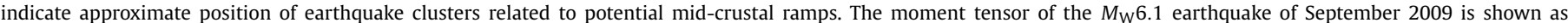

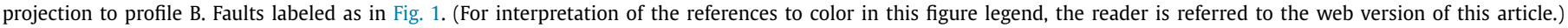

striking low-velocity zone in western Bhutan correlates with the dextral DCF in the Indian basement (A2, A3 in Fig. 4B). Velocity anomalies A4 and A5 (Fig. 4B, 4C) at mid to lower crustal levels suggest a lateral change in crustal thickness, with thicker crust in western Bhutan compared to the east. Another low velocity anomaly in the lower crust is imaged just south of the MFT (A6 in Fig. 4C), indicating structural variations or inherited structures within the incoming Indian crust. Synthetic tests suggest that resolution in this part is sufficient to image such anomaly (Fig. S3). Anomaly A6 spatially correlates with inselbergs of basement outcropping in the Brahmaputra Valley and can be interpreted as the root of a locally thickened crust, consistent with the absence of a deep foreland basin south of Bhutan (e.g., Clark and Bilham, 2008; Vernant et al., 2014). 


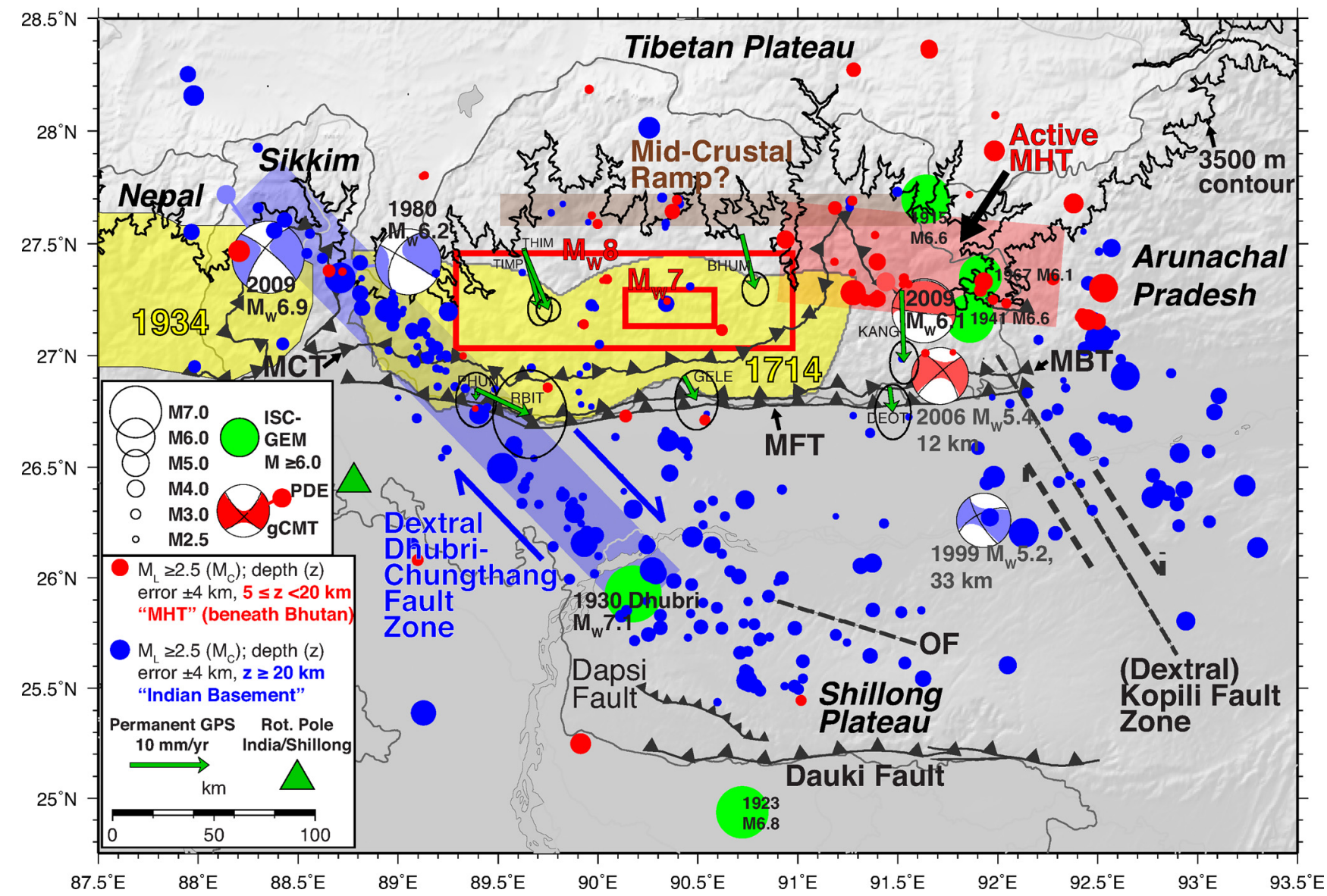

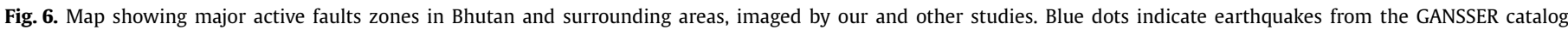

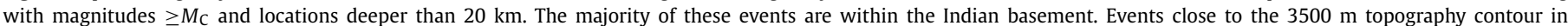

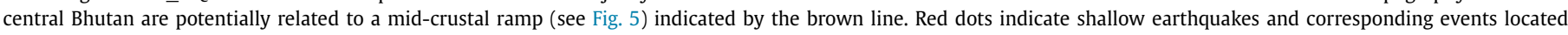

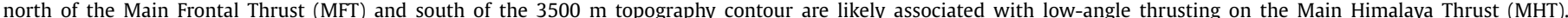

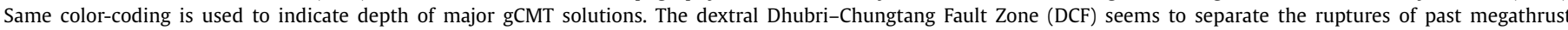

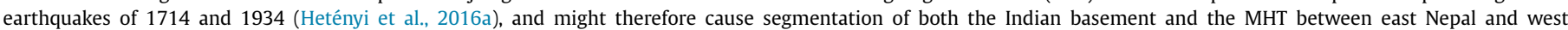

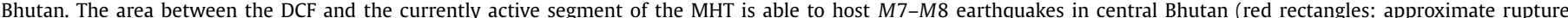

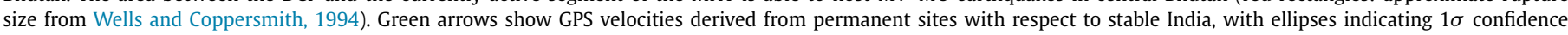

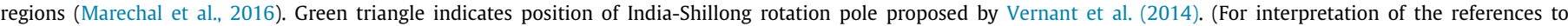
color in this figure legend, the reader is referred to the web version of this article.)

\section{Discussion}

The two most relevant tectonic structures derived in this study are: 1) The dextral DCF located in the Indian basement and its connection to foreland deformation. 2) Evidences for along-strike changes of crustal thickness, spatially correlating with variations in the seismic behavior of the MHT and the underlying basement. Both structures are discussed in the following sections, considering additional constraints from receiver functions, tomography, geology, and geodesy.

\subsection{The Dhubri-Chungthang fault zone (DCF)}

Although partly identified by others before (De and Kayal, 2003; Velasco et al., 2007), seismicity and moment tensors derived in this study solidify and extend previous indications for a NW-SE striking fault zone connecting the Sikkim Himalaya with the Shillong Plateau in the foreland. Additional evidences for a finite fault zone are provided by reduced P-wave velocities correlating with the DCF in the tomographic image (Fig. 4B), which could be related to a fault damage zone. Although recovery tests suggest that such anomaly can be resolved by our data (Fig. S3), ray-coverage and cross-firing is limited at the edge of the model and therefore artifacts due to smearing and over-shooting effects cannot be entirely excluded. The possible continuation of this anomaly towards SW is also unclear and therefore the interpretation based on the current data is not entirely conclusive. Similarly, increasing hypocenter uncertainties and the lack of focal mechanisms hamper conclusions on the precise SW termination of the DCF and potential links to bounding faults of the Shillong Plateau.

The depth distribution of seismicity within the DCF suggests that it is limited to mid and lower crustal levels (Fig. 5C, 6). The majority of earthquakes along the DCF beneath the Himalaya appear to be located below the MHT as well (Fig. 5C), which raises the question whether or not the DCF cuts across the overlying MHT, as proposed by De and Kayal (2003). A possible intersection of DCF and MHT (Fig. 7) might cause segmentation of megathrust earthquakes between eastern Nepal and western Bhutan, as suggested by the separation of the 1714 and 1934 rupture models (Figs. 6 and 7). Uncertainties of both models are consistent with spatially distinct rupture areas, which reach, at best, close to each other but do not overlap (e.g., Hetényi et al., 2016a). As proposed by Velasco et al. (2007), the alignment of the DCF with the NW-SE striking Amo-Chu valley over a length of about 30-50 km might be a geomorphological surface expression of the DCF, indicating such intersection in SW Bhutan. The absence of surface expressions of the DCF in the foreland might be explained by low deformation rates in combination with high sedimentation of the Brahmapu- 


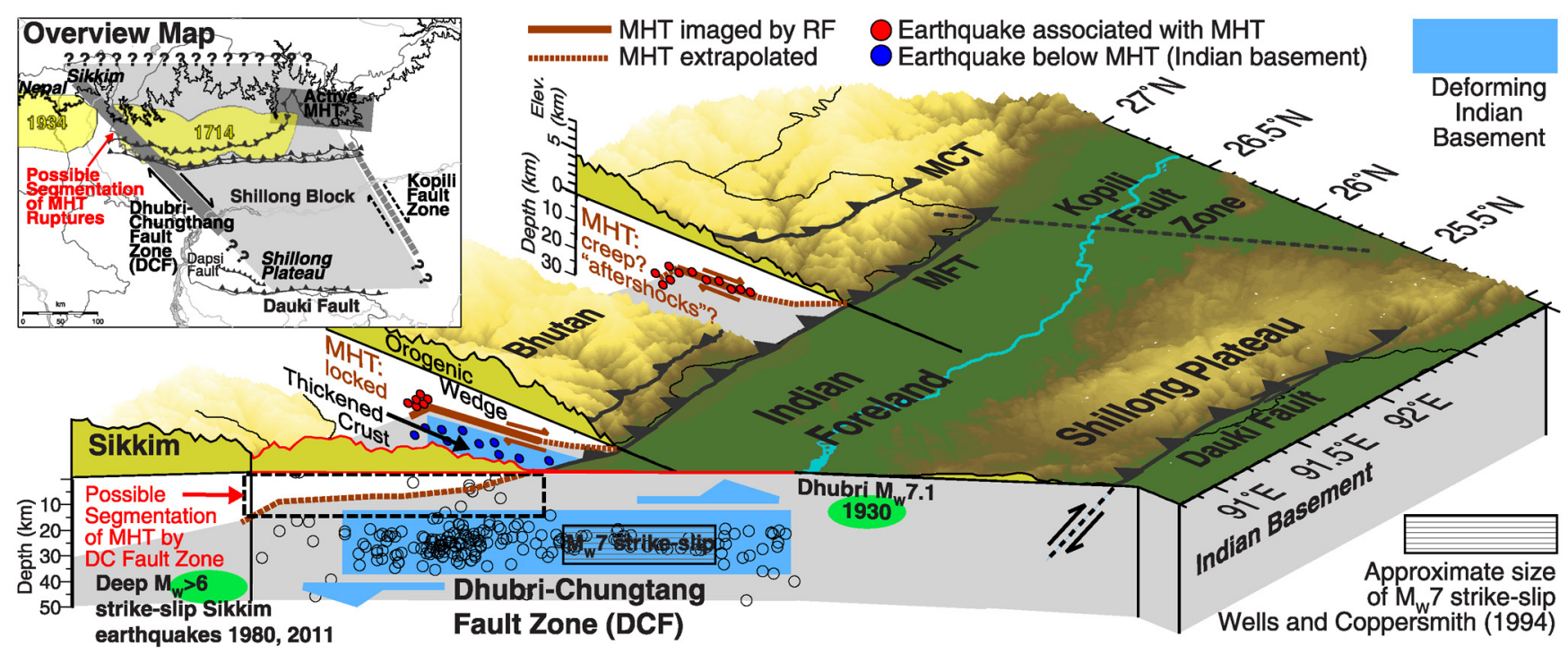

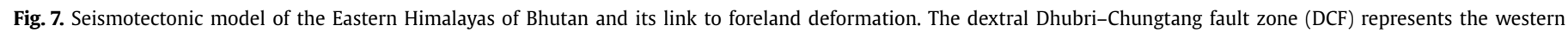

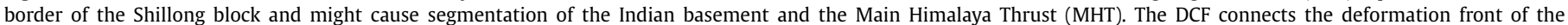

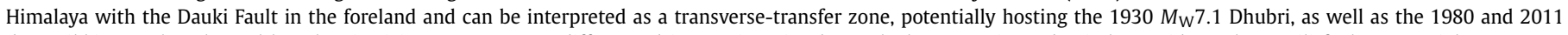

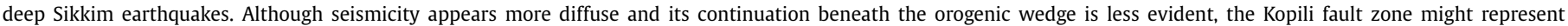

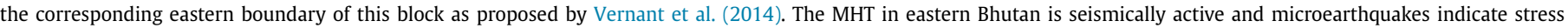
buildup above a partly deforming Indian basement in the west. The hatched rectangular indicates the approximate area of a hypothetical $M_{\mathrm{W}} 7$ strike-slip event.

tra, deleting any geomorphological signatures. Vernant et al. (2014) and Marechal et al. (2016) report eastward directed GPS velocities at sites across SW Bhutan, which deviate from the regional SSE trend (Fig. 6) and might be the surface expression of dextral slip along the DCF measured at the surface.

Based on GPS data, the tectonic model of Vernant et al. (2014) predicts clockwise rotation of the SLB, which underthrusts the Bhutan Himalaya. The model of Vernant et al. (2014) predicts $0.8 \mathrm{~mm} / \mathrm{yr}$ dextral slip along the NW-SE oriented western boundary of the SLB. The location of this boundary is based on the interpolation of surface expressions of dextral faults mapped in SE Nepal and west of the Shillong plateau (e.g., Nakata, 1989). We propose that the SLB's western boundary is instead the DCF, since it is imaged as a continuous and seismically active fault zone that segments the Indian basement. This location of the western boundary puts the Shillong-India rotation pole west of the SLB (Fig. 6), which is required to produce dextral motion on the DCF, consistent with the observed focal mechanisms as well as with the clockwise rotation of the SLB (Vernant et al., 2014).

Vernant et al. (2014) propose the Kopili fault (Fig. 6) as the eastern boundary of the SLB, accommodating 2-3 mm/yr dextral slip in their model. Compared to the DCF, seismicity appears to be diffuse in the area of the Kopili fault (Figs. 3,6) suggesting that deformation is rather distributed over a wider zone. We cannot exclude, however, that the diffuse character of seismicity results from larger location uncertainties and a dense local network might resolve a narrower fault zone. On the other hand, our results are consistent with catalogs derived from local networks in northern India, imaging a similarly broad seismogenic zone (e.g., Kayal et al., 2012). Global Centroid Moment Tensors (gCMT) west of the putative Kopili fault (Fig. 6) indicate dextral slip consistent with the model of Vernant et al. (2014) and regional moment tensors (e.g., Kayal et al., 2012; Kumar et al., 2015). With our data, however, we find no evidence for the continuation of the Kopili fault beneath the MCT in eastern Bhutan as proposed by Kayal et al. (2012). Similar to the DCF, however, the majority of seismicity associated with the Kopili fault zone appears to be located at mid to lower crustal depths, i.e. in the Indian basement (Fig. 6).

The dextral sense of the DCF implies the transfer of strain from the Himalaya to the Shillong Plateau (Figs. 6, 7) and might in- dicate an ongoing shift of the deformation front from the MFT towards the Dauki Fault in the foreland (e.g., Clark and Bilham, 2008). The strike of the DCF, however, is largely oblique to both currently active fronts (Fig. 6) and therefore differs from the common definition of transfer or tear faults, which have been proposed in other parts of the Himalayan arc (e.g., Seeber et al., 1981). The oblique orientation of the DCF might be an expression of the complex stress pattern induced by geodynamic loading of lithospheric slabs beneath the Tibetan Plateau and Burma (e.g., Li et al., 2008) or related to reactivation of a potential inherited structure in the Indian crust. In contrast to NS-striking structures like the Dhubri fault (Fig. 1), the DCF is suitably oriented for dextral strike-slip with respect to local P-axes of focal mechanisms and the direction of convergence (Figs. 3, 6). Focal depths in Fig. 5C suggest that the DCF penetrates the entire Indian crust down to the Moho. Whether or not the DCF and Kopili Faults penetrate into the mantle and therefore represent lithospheric-scale plate boundaries cannot be answered conclusively.

The DCF and Kopili fault zones have the potential to host M7 earthquakes beneath the Eastern Himalaya and the densely populated foreland basin (Fig. 7) and therefore pose a considerable hazard. Assuming an average co-seismic slip of 1-4 m for an M7 earthquake, rates of 1-3 mm/yr dextral slip predicted for the western and eastern boundaries of the SLB (e.g., Vernant et al., 2014; Barman et al., 2014) would imply recurrence intervals in the order of 300 to $4000 \mathrm{yr}$ for such a strike-slip event. Towards the NW, deep $M_{\mathrm{W}} 6.2$ and $M_{\mathrm{W}} 6.9$ strike-slip earthquakes in 1980 and 2011 are likely associated with the DCF in northern Sikkim (Figs. 6, 7). Towards its SE termination, the spatial proximity to the $M_{\mathrm{W}} 7.1$ Dhubri earthquake of 1930 (Gee, 1934; Figs. 1B, 6), previously associated with a putative NS-striking Dhubri fault (e.g., Kayal et al., 2012), favors the DCF as an alternative source fault. The macroseismic intensity field mapped by Gee (1934) for this event is biased by site effects and building types and does not allow unique conclusions on the focal mechanisms or fault orientation of the $M_{\mathrm{W}} 7.1$ main shock. Due to this lack of information and uncertainties in the location of the mainshock, other faults, such as Dhubri or Oldham, and alternative focal mechanisms, cannot be entirely excluded for the $M_{\mathrm{W}} 7.1$ Dhubri earthquake. Although slip rates are small and parts of the accumulated stresses might have been re- 
leased during the 1930 Dhubri and the deep Sikkim earthquakes, the probability of an M7 earthquake rupturing other segments of the DCF is not negligible also because previous events combined would not have ruptured the entire surface of the DCF.

\subsection{Crustal structure and MHT in Bhutan}

The imaged seismicity and crustal structure reveals distinct along-strike differences in Bhutan confirming the non-cylindrical character of the Eastern Himalaya. Lateral variations of seismic velocities imaged in the uppermost crust (Fig. 4A), suggest an inhomogeneous structure of the orogenic wedge in Bhutan, consistent with surface geology and other tomographic studies (Singer et al., 2017b). Western Bhutan is characterized by a thickened crust when compared to eastern Bhutan (Figs. 4, 5), consistent with receiver function images of the Moho (Singer et al., 2017a), which show a pronounced kink in the Moho topography south of the High Himalaya (Fig. 5A). Similarities in the shape of the $6.5 \mathrm{~km} / \mathrm{s}$ P-wave velocity contour in tomographic profiles of eastern Bhutan (Fig. 5B) and eastern Nepal (Monsalve et al., 2008) suggest that the thickened crust is limited to western Bhutan and bounded by the DCF in the west, consistent with reduced regional $P_{n}$ velocities imaged in the same area (Liang and Song, 2006). We interpret Moho topography and crustal thickening as a result of a change in geodynamic loading northwest of Bhutan, likely caused by a mantle slab attached to the underthrusting Indian lithosphere beneath the southern Tibetan Plateau (Li et al., 2008; Singer et al., 2017a). Strike-slip dominated seismicity in the Indian basement in western Bhutan (Figs. 4B, 5A) might be the expression of lateral variations of tectonic stresses induced by the proposed loading. The localized strike-slip faulting along the DCF might be another expression of stresses induced by the mantle slabs as discussed before.

Localized and scattered strike-slip faulting below the MHT implies internal deformation of the Indian basement (Fig. 7) and NS contraction rates measured by GPS at the surface in western Bhutan might therefore not be exclusively accommodated by the MHT and the Himalayan wedge. Strain therefore appears to be vertically partitioned between the MHT and internal deformation of the basement, which potentially reduces slip rates on the MHT. Whether such partitioning has a significant impact on the average recurrence time of large earthquakes or explains the apparently lower seismic activity in western and central Bhutan critically depends on the fraction of internal deformation in comparison to the total contraction rate. For example, a fraction of $10 \%$ of internal deformation would increase the recurrence time of a rupture on the MHT by a factor of 1.11. The present-day fraction of internal deformation, however, remains unclear, also because its reliable quantification requires significantly longer observation periods.

The geometry of the MHT in western Bhutan is imaged by receiver functions (Singer et al., 2017a) and micro-seismicity appears to be located in its hanging wall block, close to the predicted mid-crustal ramp about $105 \mathrm{~km}$ north of the MFT (Fig. 5A). This pattern is strikingly similar to seismicity associated with the hanging wall block in east Nepal (Monsalve et al., 2006). The seismicity at the front of the High Himalaya in western Bhutan correlates with the $3500 \mathrm{~m}$ topography contour (Fig. 5A) and with the modeled locked-to-creep transition of Vernant et al. (2014) and might therefore indicate stress buildup along a fully locked MHT, equivalent to the models for the Himalayan Seismic Belt of Nepal (e.g., Cattin and Avouac, 2000; Bollinger et al., 2004). Our observations agree well with the MHT geometry predicted by the geological model of Coutand et al. (2014) and are incompatible with the wide décollement proposed by Le Roux-Mallouf et al. (2015) and Marechal et al. (2016) (Fig. 5A). The discrepancy in geometry be- tween geological models and geophysical images might reflect differences in the considered timescales (e.g., Marechal et al., 2016).

Receiver-function converters together with the imaged shallow, sub-horizontal cluster of seismicity suggests a flat, seismogenic MHT in eastern Bhutan (Fig. 5B). The position of this cluster correlates with the hypocenter of the $M_{\mathrm{W}} 6.1$ earthquake of September 2009 (Fig. 3), and the dip of the corresponding gCMT lowangle thrust solution agrees well with the dip resolved by microearthquakes, receiver functions, and the geological MHT model of Coutand et al. (2014) (Fig. 5B). Based on an alternative moment tensor solution with an additional strike-slip component not apparent in the gCMT mechanisms, Kayal et al. (2012) associate the $2009 M_{\mathrm{W}} 6.1$ event with the dextral Kopili fault, potentially extending it towards the MCT in eastern Bhutan. Our relocations show no evidence for a seismogenic, sub-vertical Kopili fault extending to this area (Figs. 3, 5B) and argue that the geometry of the observed seismicity favors a sub-horizontal thrust ruptured in 2009. A relation between the observed seismicity in Fig. 5B and the 2009 rupture is also backed up by the absence of seismicity in the area prior to the $2009 M_{\mathrm{W}} 6.1$ event in global (Fig. 1) and local (Velasco et al., 2007) earthquake catalogs. It is arguable, however, if the observed seismicity $4-5 \mathrm{yr}$ after an $M_{\mathrm{W}} 6.1$ event can still be considered as aftershock activity. Duration of aftershock activity varies largely (e.g., Stein and Liu, 2009) and therefore an increased background level cannot be excluded, also because the seismic network is rather sensitive in this region (Fig. S1). Alternatively, the observed seismicity in Fig. 5B might be interpreted as swarm-activity following the $M_{\mathrm{W}} 6.1$ event, which is potentially driven by a partially creeping MHT. Marechal et al. (2016) propose such partially creeping segments along the MHT based on slip-rate models derived from GPS data in eastern Bhutan. However, the flat segment between 25 and $105 \mathrm{~km}$ north of the MFT appears to be almost fully locked in their model, making it less likely that the sub-horizontal seismicity is related to significant creep on the MHT.

The abrupt deepening of seismicity $95 \mathrm{~km}$ north of the MFT (Fig. 5B) indicates a steep mid-crustal ramp in eastern Bhutan, potentially creeping as proposed by Marechal et al. (2016). GPS velocities in the region $100 \mathrm{~km}$ north of the MFT are, however, poorly sampled along their eastern profile. Potential modeling uncertainties as well as significant differences in the MHT geometries (i.e. length of flat portion) therefore hamper a detailed comparison of modeled slip-rates with seismicity on the mid-crustal ramp. Also the geological model of Coutand et al. (2014) suggests the existence of a ramp, its geometry, however, is not well constrained by their data, which might explain the differences between seismicity and their model (Fig. 5B). Likewise, the geometry of such ramp is not well resolved by receiver functions, however, indications for a sub-horizontal Moho in NE Bhutan argue against a steep ramp (Singer et al., 2017a). Otherwise, this cluster might be related to a fault rooting in the footwall block of the MHT, but the similarity in position to the corresponding ramp in western Bhutan suggests the existence of a similar geometry in the east. The absence of seismicity in the hanging wall block, as observed in the west, underpins potential differences in current stress buildup on the MHT between eastern and western Bhutan.

Whether or not the imaged seismogenic segment is related to a partially creeping MHT and whether or not the Kopili fault segments the MHT in eastern Bhutan, the MHT bounded by the DCF in the west and the seismogenic segment in the east can host $M 7-8$ earthquakes as shown by approximate rupture areas in Fig. 6, derived from empirical relationships. A scenario, in which the slip of $5 \mathrm{~m}$, potentially cumulated since the 1714 event, is released by a rupture of a locked portion of the MHT (down-dip width of about $100 \mathrm{~km}$, Fig. 5), segmented by the DCF and the Kopili fault (alongstrike length of about $240 \mathrm{~km}$, Fig. 6), would actually result in an 
$M_{\mathrm{W}}$ of 8.4. Evidence for past megathrust ruptures in the Bhutan Himalaya have been provided by other recent studies (e.g., Berthet et al., 2014; Le Roux-Mallouf et al., 2016; Hetényi et al., 2016a) and similar structural segmentation is suggested from gravity anomalies (Hetényi et al., 2016b).

\section{Conclusion}

In this study, we derived the first high-resolution earthquake catalog and 3-D crustal $V_{P}$ model for Bhutan from the GANSSER passive seismic experiment. In combination with receiver function images, our results significantly solidify and extend the previously sparse knowledge on the crustal structure and active faults in Bhutan and therefore provide important new constraints for understanding the tectonic processes in the Eastern Himalayas and its foreland. The imaged along-strike changes in crustal structure and seismicity show that the region between Sikkim and western Bhutan represents a major boundary in the Himalayas, consistent with geological (e.g. absence of a foredeep, Dasgupta et al., 2000) and other geophysical observation (e.g., Hetényi et al., 2016b) and confirm the non-cylindrical character of the Eastern Himalaya.

The obliquely striking, dextral Dhubri-Chungthang Fault Zone (DCF) segments the Indian basement and potentially causes segmentation of the MHT between eastern Nepal and western Bhutan. It appears to connect the deformation fronts of the Himalaya with the Shillong Plateau in the foreland and we propose the DCF as the western boundary of the previously defined Shillong block, which underthrusts the Bhutan Himalaya. A low velocity anomaly in the lower crust in the foreland just south of the MFT spatially correlates with outcropping basement in the Brahmaputra Valley and can be interpreted as the root of a locally thickened crust, consistent with the absence of a deep foreland basin south of Bhutan.

A thickened crust and strike-slip seismicity within the Indian basement in western Bhutan might be expressions of laterally changing stresses in the Eastern Himalayas. Clusters of microearthquakes in front of the High Himalayas indicate the presence of a mid-crustal ramp about $100 \mathrm{~km}$ north of the MFT. Considering recent slip-models derived from GPS data, seismicity in western and central Bhutan suggests stress buildup on a fully coupled MHT above a partly deforming basement. Contraction rates measured by GPS at the surface in western Bhutan might therefore not be exclusively accommodated by the MHT décollement. Strain appears to be partitioned between the MHT and internal deformation of the basement. Whether such partitioning has a significant impact on the average recurrence time of large earthquakes or explains the apparently lower instrumental seismic activity in western and central Bhutan remains unclear, also because its reliable quantification requires significantly longer observation periods.

In eastern Bhutan, seismicity images a flat, seismogenic segment of the MHT, either related to an $M_{\mathrm{W}} 6.1$ earthquake in 2009 or indicating a partially creeping fault segment. The area bounded by the DCF in the west and the seismogenic MHT in the east has the potential for M7-8 earthquakes in Bhutan. Similarly, the DCF has the potential to host $M 7$ earthquakes beneath the Himalaya and the densely populated foreland basin as documented by the 2011 Sikkim and the 1930 Dhubri earthquakes, which were potentially associated with this structure.

\section{Acknowledgements}

Comments by Roger Bilham and one anonymous reviewer helped to improve the manuscript and are thankfully acknowledged. We thank S. Schmid, J.-P. Burg, C. Cauzzi, and T. Tormann for helpful discussions. This work and the deployment of the temporary seismic GANSSER network in Bhutan were funded by the Swiss National Science Foundation (SNF), Grant 200021_143467
(G. Hetényi). The GANSSER acronym was chosen to commemorate the famous geologist Augusto Gansser (1910-2012). D. Grujic thanks the ETH Zurich Visiting Professorship Fund for financial support during the preparation of the manuscript at the Institute of Geophysics (ETH Zurich). The instrument pool of the SED and Seismology and Geodynamics (SEG) group at ETH Zurich provided the station hardware. We thank D. Drukpa and his colleagues at the Department of Geology and Mines of the Kingdom of Bhutan for support during the fieldwork. We thankfully acknowledge also the GANSSER fieldwork team. We thank S. Mitra from the Indian Institute of Science Education and Research Kolkata (IISER Kolkata) for providing phase data for selected events of stations in Sikkim and West Bengal. Moment tensor inversions were derived by the SCMTV-software provided by GFZ Potsdam/GEMPA GmbH.

\section{Appendix A. Supplementary material}

Supplementary material related to this article can be found online at http://dx.doi.org/10.1016/j.epsl.2017.04.038.

\section{References}

Avouac, J., Meng, L., Wei, S., Wang, T., Ampuero, J., 2015. Lower edge of locked Main Himalayan Thrust unzipped by the 2015 Gorkha earthquake. Nat. Geosci. 8, 708-711. http://dx.doi.org/10.1038/ngeo2518.

Banerjee, P., Bürgmann, R., Nagarajan, B., Apel, E., 2008. Intraplate deformation of the Indian subcontinent. Geophys. Res. Lett. 35 (18), L18,301. http://dx.doi.org/ 10.1029/2008GL035468.

Barman, P., Ray, J., Kumar, A., Chowdhury, J.D., Mahanta, K., 2014. Estimation of present-day inter-seismic deformation in Kopili fault zone of North-East India using GPS measurements. Geomat. Nat Hazards Risk 7, 586-599. http:// dx.doi.org/10.1080/19475705.2014.983187.

Berthet, T., Ritz, J.F., Ferry, M., Pelgay, P., Cattin, R., Drukpa, D., Braucher, R., Hetényi, G., 2014. Active tectonics of the eastern Himalaya: new constraints from the first tectonic geomorphology study in southern Bhutan. Geology 42 (5), 427-430. http://dx.doi.org/10.1130/G35162.1.

Bilham, R., England, P., 2001. Plateau 'pop-up' in the great 1897 Assam earthquake. Nature 410 (6830), 806-809. http://dx.doi.org/10.1038/35071057.

Biswas, S., Coutand, I., Grujic, D., Hager, C., Stöckli, D., Grasemann, B., 2007. Exhumation and uplift of the Shillong plateau and its influence on the eastern Himalayas: new constraints from apatite and zircon (U-Th-[Sm])/He and apatite fission track analyses. Tectonics 26, TC6013. http://dx.doi.org/ 10.1029/2007TC002125.

Bollinger, L., Avouac, J.P., Cattin, R., Pandey, M.R., 2004. Stress buildup in the Himalaya. J. Geophys. Res. 109, B11405. http://dx.doi.org/10.1029/2003JB002911.

Burgess, W.P., Yin, A., Dubey, C.S., Shen, Z.-K., Kelty, T.K., 2012. Holocene shortening across the main frontal thrust zone in the eastern Himalaya. Earth Planet. Sci. Lett. 357-358, 152-167. http://dx.doi.org/10.1016/j.epsl.2012.09.040.

Cattin, R., Avouac, J.P., 2000. Modeling mountain building and the seismic cycle in the Himalaya of Nepal. J. Geophys. Res., Solid Earth 105 (B6), 13,389-13,407. http://dx.doi.org/10.1029/2000JB900032.

Clark, M.K., Bilham, R., 2008. Miocene rise of the Shillong Plateau and the beginning of the end for the Eastern Himalaya. Earth Planet. Sci. Lett. 269 (3-4), 337-351. http://dx.doi.org/10.1016/j.epsl.2008.01.045.

Coutand, I., Whipp, D.M., Grujic, D., Bernet, M., Fellin, M.G., Bookhagen, B., Landry, K.R., Ghalley, S.K., Duncan, C., 2014. Geometry and kinematics of the Main Himalayan Thrust and Neogene crustal exhumation in the Bhutanese Himalaya derived from inversion of multithermochronologic data. J. Geophys. Res., Solid Earth 119, 1446-1481. http://dx.doi.org/10.1002/2013JB010891.

Dasgupta, S., Mukhopadhyay, M., Nandy, D.R., 1987. Active transverse features in the central portion of the Himalaya. Tectonophysics 136, 255-264. http://dx.doi.org/ 10.1016/0040-1951(87)90028-X.

Dasgupta, S., et al., 2000. Seismotectonic atlas of India and its environs. In: Narula, P.L., Acharyya, S.K., Banerjee, J. (Eds.), Geological Survey of India. Calcutta, India, $87 \mathrm{pp}$

De, R., Kayal, J.R., 2003. Seismotectonic model of the Sikkim Himalaya: constraint from microearthquake surveys. Bull. Seismol. Soc. Am. 93 (3), 1395-1400. http:// dx.doi.org/10.1785/0120020211.

Drukpa, D., Velasco, A.A., Doser, D.I., 2006. Seismicity in the kingdom of Bhutan (1937-2003): evidence for crustal transcurrent deformation. J. Geophys. Res. 111, B06301. http://dx.doi.org/10.1029/2004JB003087.

Eberhart-Phillips, D., 1990. Three-dimensional $\mathrm{P}$ and $\mathrm{S}$ velocity structure in the Coalinga region, California. J. Geophys. Res. 95, 15343-15363. http://dx.doi.org/ 10.1029/JB095iB10p15343.

England, P., Bilham, R., 2015. The Shillong Plateau and the great 1897 Assam earthquake. Tectonics 34, 1792-1812. http://dx.doi.org/10.1002/2015TC003902. 
Gahalaut, V., Rajput, S., Kundu, B., 2011. Low seismicity in the Bhutan Himalaya and the stress shadow of the 1897 Shillong Plateau earthquake. Phys. Earth Planet. Inter. 186. http://dx.doi.org/10.1016/j.pepi.2011.04.009.

Gee, E.R., 1934. The Dhubri earthquake of July 8, 1930. Mem. Geol. Surv. India 65 (part 1), $106 \mathrm{pp}$

Hanka, W., Saul, J., Weber, B., Becker, J., Harjadi, P., Fauzi, GITEWS Seismology Group, 2010. Real-time earthquake monitoring for tsunami warning in the Indian Ocean and beyond. Nat. Hazards Earth Syst. Sci. 10, 2611-2622. http:// dx.doi.org/10.5194/Nhess-10-2611-2010.

Hauck, M., Nelson, K., Brown, L., Zhao, W., Ross, A., 1998. Crustal structure of the Himalayan orogen at $\sim 90^{\circ}$ East longitude from Project INDEPTH deep reflection profiles. Tectonics 17, 481-500. http://dx.doi.org/10.1029/98TC01314.

Hetényi, G., Cattin, R., Berthet, T., Moigne, N., Chophel, J., Lechmann, S., Hammer, P., Drukpa, D., Sapkota, S., Gautier, S., Thinley, K., 2016b. Segmentation of the Himalayas as revealed by arc-parallel gravity anomalies. Sci. Rep. 6, 33866. http:// dx.doi.org/10.1038/srep33866.

Hetényi, G., Le Roux-Mallouf, R., Berthet, T., Cattin, R., Cauzzi, C., Phuntsho, K., Grolimund, R., 2016a. Joint approach combining damage and paleoseismology observations constrains the 1714 A.D. Bhutan earthquake at magnitude $8 \pm 0.5$. Geophys. Res. Lett. 43, 10,695-10,702. http://dx.doi.org/10.1002/2016GL071033.

Kayal, J.R., Arefiev, S.S., Baruah, S., Hazarika, Gogoi, Gautam, J.L., Baruah, S., Dorbath, Tatevossian, 2012. Large and great earthquakes in the Shillong plateau-Assam valley area of Northeast India Region: pop-up and transverse tectonics. Tectonophysics 532, 186-192. http://dx.doi.org/10.1016/j.tecto.2012.02.007.

Kumar, A., Mitra, S., Suresh, G., 2015. Seismotectonics of the eastern Himalayan and Indo-Burman plate boundary systems. Tectonics 34, 2279-2295. http:/| dx.doi.org/10.1002/2015TC003979.

Le Roux-Mallouf, R., Godard, V., Cattin, R., Ferry, M., Gyeltshen, J., Ritz, J., Drupka, D., Guillou, V., Arnold, M., Aumaître, G., Bourlès, D., Keddadouche, K., 2015. Evidence for a wide and gently dipping Main Himalayan Thrust in western Bhutan. Geophys. Res. Lett. 42, 3257-3265. http://dx.doi.org/10.1002/2015GL063767.

Le Roux-Mallouf, R., Ferry, M., Ritz, J.-F., Berthet, T., Cattin, R., Drukpa, D., 2016. First paleoseismic evidence for great surface-rupturing earthquakes in the Bhutan Himalayas. J. Geophys. Res., Solid Earth 121, 7271-7283. http://dx.doi.org/ 10.1002/2015JB012733.

Li, C., van der Hilst, R.D., Meltzer, A.S., Engdahl, E.R., 2008. Subduction of the Indian lithosphere beneath the Tibetan Plateau and Burma. Earth Planet. Sci. Lett. 274 (1-2), 157-168. http://dx.doi.org/10.1016/j.epsl.2008.07.016.

Liang, C., Song, X., 2006. A low velocity belt beneath northern and eastern Tibetan Plateau from $P_{n}$ tomography. Geophys. Res. Lett. 33, L22306. http://dx.doi.org/ 10.1029/2006GL027926.

Lomax, A., Virieux, J., Volant, P., Thierry-Berge, C., 2000. Probabilistic earthquake location in 3D and layered models. In: Advances in Seismic Event Location, pp. 101-134. http://books.google.ch/books?id=wIBMjf_fWTIC.

Long, S., McQuarrie, N., Tobgay, T., Grujic, D., Hollister, L., 2011. Geologic map of Bhutan. J. Maps 7, 184-192. http://dx.doi.org/10.4113/jom.2011.1159.

Marechal, A., Mazzotti, S., Cattin, R., Cazes, G., Vernant, P., Drukpa, D., Thinley, K., Tarayoun, A., Le Roux-Mallouf, R., Thapa, B., Pelgay, P., Gyeltshen, J., Doerflinger, E., Gautier, S., 2016. Evidence of interseismic coupling variations along the Bhutan Himalayan arc from new GPS data. Geophys. Res. Lett. 43 (12), 12399-12406. http://dx.doi.org/10.1002/2016gl071163.

Monsalve, G., Sheehan, A., Schulte-Pelkum, V., Rajaure, S., Pandey, M.R., Wu, F., 2006. Seismicity and one-dimensional velocity structure of the Himalayan collision zone: earthquakes in the crust and upper mantle. J. Geophys. Res., Solid Earth 111, B10301. http://dx.doi.org/10.1029/2005jb004062.

Monsalve, G., Sheehan, A., Rowe, C., Rajaure, S., 2008. Seismic structure of the crust and the upper mantle beneath the Himalayas: evidence for eclogitization of lower crustal rocks in the Indian Plate. J. Geophys. Res., Solid Earth 113, B08315. http://dx.doi.org/10.1029/2007JB005424.

Nakata, T., 1989. Active faults of the Himalaya of India and Nepal. Geol. Soc. Am. Spec. Pap. 232, 243-264. http://dx.doi.org/10.1130/SPE232-p243.

Paul, H., Mitra, S., Bhattacharya, S.N., Suresh, G., 2015. Active transverse faulting within underthrust Indian crust beneath the Sikkim Himalaya. Geophys. J Int. 201, 1072-1083. http://dx.doi.org/10.1093/gji/ggv058.

Richter, C.F., 1935. An instrumental earthquake magnitude scale. Bull. Seismol. Soc Am. 25, 1-32.

Schorlemmer, D., Woessner, J., 2008. Probability of detecting an earthquake. Bull. Seismol. Soc. Am. 98, 2103-2117. http://dx.doi.org/10.1785/0120070105.

Schorlemmer, D., Wiemer, S., Wyss, M., 2005. Variations in earthquake-size distribution across different stress regimes. Nature 437, 539-542. http://dx.doi.org/ 10.1038 /nature04094.

Seeber, L., Armbruster, J.G., Quittmeyer, R., 1981. Seismicity and continental subduction in the Himalayan Arc, in Zagros, Hindu Kush, Himalaya. In: Gupta, H.K. Delany, F.M. (Eds.), Geodynamic Evolution. In: Geodyn. Ser., vol. 3, pp. 215-242.

Singer, J., Kissling, E., Diehl, T., Hetényi, G., 2017a. The underthrusting Indian crust and its role in collision dynamics of the eastern Himalaya of Bhutan: insights from receiver function imaging. J. Geophys. Res., Solid Earth 122, 1152-1178. http://dx.doi.org/10.1002/2016jb013337.

Singer, J., Obermann, A., Kissling, E., Fang, H., Hetényi, G., Grujic, D., 2017b. Alongstrike variations in the Himalayan orogenic wedge structure in Bhutan from ambient seismic noise tomography. Geochem. Geophys. Geosyst. 18. http:// dx.doi.org/10.1002/2016GC006742.

Stein, S., Liu, M., 2009. Long aftershock sequences within continents and implications for earthquake hazard assessment. Nature 462, 87-89. http://dx.doi.org 10.1038 /nature08502.

Stevens, V., Avouac, J.P., 2016. Millenary $M_{\mathrm{W}}>9.0$ earthquakes required by geodetic strain in the Himalaya. Geophys. Res. Lett. 43, 1118-1123. http://dx.doi.org/ 10.1002/2015GL067336.

Storchak, D.A., Di Giacomo, D., Bondár, I., Engdahl, E.R., Harris, J., Lee, W.H.K., Villaseñor, A., Bormann, P., 2013. Public release of the ISC-GEM global instrumental earthquake catalogue (1900-2009). Seismol. Res. Lett. 84, 810-815. http:// dx.doi.org/10.1785/0220130034.

Swiss Seismological Service (SED) at ETH Zurich, 2013. GANSSER Broadband Seismic Experiment in Bhutan, ETH Zurich, Other/Seismic Network https://doi.org/10.12686/sed/networks/xa.

Thirunavukarasu, A., Kumar, A., Mitra, S., 2017. Lateral variation of seismic attenuation in Sikkim Himalaya. Geophys. J. Int. 208, 257-268. http://dx.doi.org/ $10.1093 / \mathrm{gji} / \mathrm{ggw} 384$

Velasco, A.A., Gee, V.L., Rowe, C., Grujic, D., Hollister, L.S., Hernandez, D., Miller, K.C. Tobgay, T., Fort, M., Harder, S., 2007. Using small, temporary seismic networks for investigating tectonic deformation: brittle deformation and evidence for strike-slip faulting in Bhutan. Seismol. Res. Lett. 78, 446-453. http://dx.doi.org/ 10.1785/gssrl.78.4.446.

Vernant, P., Bilham, R., Szeliga, W., Drupka, D., Kalita, S., Bhattacharyya, A.K., Gaur, V.K., Pelgay, P., Cattin, R., Berthet, T., 2014. Clockwise rotation of the Brahmaputra Valley relative to India: tectonic convergence in the eastern Himalaya, Naga Hills, and Shillong Plateau. J. Geophys. Res., Solid Earth 119 (8), 6558-6571. http://dx.doi.org/10.1002/2014JB011196.

Waldhauser, F., Ellsworth, W., 2000. A double-difference earthquake location algorithm: method and application to the northern Hayward Fault, California. Bull. Seismol. Soc. Am. 90, 1353-1368. http://dx.doi.org/10.1785/0120000006.

Wells, D.L., Coppersmith, K.J., 1994. New empirical relationships among magnitude rupture length, rupture width, rupture area, and surface displacement. Bull. Seismol. Soc. Am. 84 (4), 974-1002, A1-A4, B1-B11, C1-C49. 